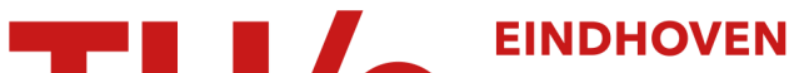 UNIVERSITY OF TECHNOLOGY
}

\section{Ultra-low surface recombination for deeply etched III-V semiconductor nano-cavity lasers}

\section{Citation for published version (APA):}

Higuera Rodriguez, A., Patarata Romeira, B. M., Birindelli, S., Black, L. E., Smalbrugge, E., Kessels, W. M. M., Smit, M. K., \& Fiore, A. (2016). Ultra-low surface recombination for deeply etched III-V semiconductor nanocavity lasers. In Proceedings Advanced Photonics 2016 (IPR, NOMA, Sensors, Networks, SPPCom, SOF) [ITu2A.2] OSA Publishing. https://doi.org/10.1364/IPRSN.2016.ITu2A.2

DOI:

10.1364/IPRSN.2016.ITU2A.2

Document status and date:

Published: 01/01/2016

\section{Document Version:}

Publisher's PDF, also known as Version of Record (includes final page, issue and volume numbers)

\section{Please check the document version of this publication:}

- A submitted manuscript is the version of the article upon submission and before peer-review. There can be important differences between the submitted version and the official published version of record. People interested in the research are advised to contact the author for the final version of the publication, or visit the $\mathrm{DOI}$ to the publisher's website.

- The final author version and the galley proof are versions of the publication after peer review.

- The final published version features the final layout of the paper including the volume, issue and page numbers.

Link to publication

\section{General rights}

Copyright and moral rights for the publications made accessible in the public portal are retained by the authors and/or other copyright owners and it is a condition of accessing publications that users recognise and abide by the legal requirements associated with these rights.

- Users may download and print one copy of any publication from the public portal for the purpose of private study or research.

- You may not further distribute the material or use it for any profit-making activity or commercial gain

- You may freely distribute the URL identifying the publication in the public portal.

If the publication is distributed under the terms of Article 25fa of the Dutch Copyright Act, indicated by the "Taverne" license above, please follow below link for the End User Agreement:

www.tue.nl/taverne

Take down policy

If you believe that this document breaches copyright please contact us at:

openaccess@tue.nl

providing details and we will investigate your claim. 


\title{
Ultra-low surface recombination for deeply etched III-V semiconductor nano-cavity lasers
}

\author{
A. Higuera-Rodriguez", B. Romeira, S. Birindelli, L. Black, B. Smalbrugge, W. M. M. Kessels M. K. \\ Smit, and A. Fiore. \\ COBRA Research Institute, Eindhoven University of Technology, Postbox 513, 5600 MB Eindhoven, The Netherlands \\ *Authore-mail address: A.Higuera.Rodriguez@tue.nl
}

\begin{abstract}
We investigated the passivation of III-V semiconductor nanostructures using wet-chemical ammonium sulfide treatment and $\mathrm{SiO}_{\mathrm{x}}$ encapsulation. We achieved an ultra-low surface recombination velocity value of $\sim 530 \mathrm{~cm} / \mathrm{s}$ enabling the future development of high-performance room-temperature nanolasers.

OCIS codes: (140.0140) Lasers and laser optics; (160.0160) Materials; (250.5300) Photonic Integrated Circuits; (250.5980) Semiconductor Optical amplifiers
\end{abstract}

\section{Introduction}

In the last few years, many nanoscale light sources have been reported, such as nanocavity lasers employing III$\mathrm{V}$ materials as the gain medium [1,2]. Scaling down the laser sources to the size below their operation wavelength $(<1.5 \mu \mathrm{m})$ will greatly contribute for the deployment of on-chip optical interconnects thanks to their small footprint, low energy consumption and high speed [2]. Despite recent efforts, difficulties in achieving room temperature (RT) and continues wavelength $(\mathrm{CW})$ operation with high output optical power considerably limits the use of nanolasers in future optical communication systems. Among many challenges, non-radiative processes including surface recombination have been shown to have a detrimental effect in the efficiency of deeply etched $p n$-junctions such as in sub-wavelength cavity nanolasers [2]. Due to the high surface-to-volume ratio of such nanostructures, large areas of the active material are exposed with a high density of non-radiative recombination centers formed from the bombardment of high energy ions during etching. As the size of the active region becomes comparable with the carrier diffusion length, surface effects begin to strongly influence their performance. Since the non-radiative processes reduce the radiative efficiency, the threshold current of a nanolaser increases as the injected carriers recombine faster [3]. Therefore, the reduction of non-radiative centers is a key factor for enabling RT at CW operation in nanolasers.

Although surface recombination strongly limits the performance of sub- $\mu \mathrm{m}$ devices, passivation treatments of the surface of nanoscale III-V semiconductor heterostructures have remained almost unexplored apart from a recently published photonic crystal nanolaser $[1,3]$ reporting a 3 -fold reduction of the surface velocity $\left(\mathrm{S}=4 \times 10^{3}\right.$ $\mathrm{cm} / \mathrm{s})$ when compared to best values obtained in $[4]\left(\mathrm{S}=1.2 \times 10^{4} \mathrm{~cm} / \mathrm{s}\right)$. Here, we report ultra-low surface velocities for sub- $\mu \mathrm{m} \mathrm{III-V}$ deeply etched nanopillars using a sulfide passivation treatment that comprises a gentle wet etching of the active material plus ammonium sulfide solution at $20 \%$ followed by a thin $\mathrm{SiO}_{\mathrm{x}}$ capping. We observed a very robust passivation effect that enhances the photoluminescence (PL) up to two orders of magnitude compare with un-passivated samples. Time-resolved microPL measurements further confirm the substantial improvements showing two orders of magnitude increase of the carrier life times and allowing us to estimate an ultra-low surface recombination of $S \sim 530 \mathrm{~cm} / \mathrm{s}$, which, to our knowledge is a record for nano structures. Most importantly, this ultralow surface recombination is a key enabler for the future development of efficient, high power, and room-temperature electrically pumped nanocavity lasers.

\section{Fabrication and Technology}

A series of experiments were performed to test $\left(\mathrm{NH}_{4}\right)_{2} \mathrm{~S}$ (ammonium sulfide) plus thin $\mathrm{SiO}_{\mathrm{x}}$ capping passivation on undoped InP/InGaAs/InP nano-pillars. The layer stack is a $p n$-junction of InP with bulk InGaAs ( $350 \mathrm{~nm}$ thickness) material as shown in Figure1 a). The sample comprises 7 equal patterns of two rows; each with 15 square pillars. The pillars side ranged from $270 \mathrm{~nm}$ to $3.4 \mu \mathrm{m}$.

The fabrication involved electron beam lithography (EBL), followed by dry etching with inductively coupled plasma (ICP) to etch the pillars until $\sim 1 \mu \mathrm{m}$ depth. It included wet etching steps plus oxygen plasma treatment to clean the surface of the pillars. Figure 1a-d) shows the schematic of the pillar after being capped by $\mathrm{SiO}_{\mathrm{x}}$ and 
Scanning Electron Microscope (SEM) pictures of the pillar array, a $1 \mu \mathrm{m}$ cross-section side pillar, the top view of a pillar with $2.7 \mu \mathrm{m}$ side and the smallest test pillar with $270 \mathrm{~nm}$ side.

The samples, named R1-Q1 to R1-Q7 were tested with two different passivation approaches: both processes started with a standard oxygen plasma cleaning of 10 minutes at $300 \mathrm{~W}$ plus 2 minutes into diluted $\mathrm{H}_{3} \mathrm{PO}_{4}$ followed by $10 \mathrm{~s}$ gentle etching of the active material done by $\mathrm{H}_{2} \mathrm{O}: \mathrm{H}_{2} \mathrm{SO}_{4}: \mathrm{H}_{2} \mathrm{O}_{2}(5000: 1: 8)$. After that, the samples were divided for different tests as Table 1 in Figure 2a) shows. The first test comprised 5 cycles of oxygen plasma plus wet chemical cleaning of 2 minutes with $\mathrm{H}_{3} \mathrm{PO}_{4}$ followed by rinsing with ultra-pure water (UPW) and drying with an $\mathrm{N}_{2}$ pistol. The second test implied ammonium sulfide as passivation agent where the samples were submerged in a solution of 100:10 $\mathrm{H}_{2} \mathrm{O}:\left(\mathrm{NH}_{4}\right)_{2} \mathrm{~S}-20 \%$ solution during 5 minutes [3, 4].

For each test a thin cap layer of $50 \mathrm{~nm} \mathrm{SiO}$, or $10 \mathrm{~nm} \mathrm{Al}_{2} \mathrm{O}_{3}$ was deposited on top of the pillars to obtain a lasting passivation. The deposition was done either with Plasma Enhanced Chemical Vapor Deposition (PECVD) at $300 \mathrm{C}$ or Atomic Layer Deposition (ALD) at $150 \mathrm{C}$ (see figure $2 \mathrm{a}$ )), the deposition was performed right after the oxygen plasma or ammonium sulfide passivation processes.
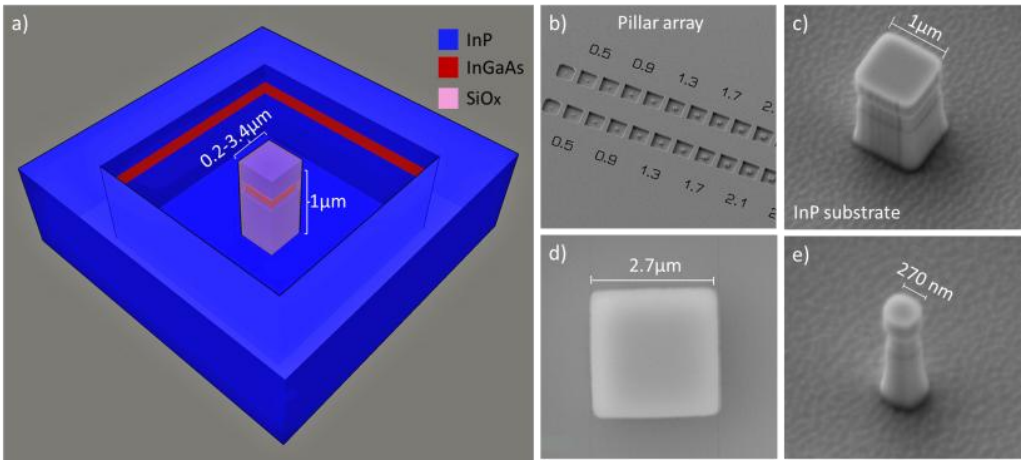

Figure1 a) Schematic of a pillar with thin cap of $\mathrm{SiO}_{\mathrm{x}}$, b) Fabricated pillar array, c) $1 \mu \mathrm{m}$ pillar cross-section side, d) Top view of a $2.7 \mu \mathrm{m}$ pillar, e) Smallest etched pillar of $270 \mathrm{~nm}$ cross-section side.

\begin{tabular}{|c|c|}
\hline Sample & Passivation method \\
\hline R1-Q1 & cleaning \\
\hline R1-Q2 & $\begin{array}{l}5 \text { cycles } 10 \mathrm{~min} \text { oxygen plasma at } 300 \mathrm{~W} \\
+2 \mathrm{~min}_{3} \mathrm{PO}_{4}\end{array}$ \\
\hline R1-Q3 & $5 \min \left(\mathrm{NH}_{4}\right)_{2} \mathrm{~S}$ \\
\hline R1-Q4 & $\begin{array}{l}5 \text { cycles } 10 \mathrm{~min} \text { oxygen plasma at } 300 \mathrm{~W} \\
+2 \mathrm{~min} \mathrm{H}_{3} \mathrm{PO}_{4}+50 \mathrm{~mm} \quad \mathrm{SiO}_{x} \text { after } \\
1^{\prime} 40^{\prime \prime} \text { in } \mathrm{PECVD}\end{array}$ \\
\hline R1-Q5 & $\begin{array}{l}5 \mathrm{~min}\left(\mathrm{NH}_{4}\right)_{2} \mathrm{~S}+50 \mathrm{~nm} \quad \mathrm{SiO}_{x} \text { after } \\
1^{\prime} 40^{\prime \prime} \text { in PECVD }\end{array}$ \\
\hline R1-Q6 & $\begin{array}{l}5 \min \left(\mathrm{NH}_{4}\right)_{2} \mathrm{~S}+10 \mathrm{~nm} \quad \mathrm{Al}_{2} \mathrm{O}_{3} \text { after } \\
1^{\prime} 40^{\prime \prime} \text { in ALD }\end{array}$ \\
\hline R1-Q7 & $\begin{array}{l}5 \text { cycles } 10 \mathrm{~min} \text { oxygen plasma at } 300 \mathrm{~W} \\
+2 \mathrm{~min} \mathrm{H}_{3} \mathrm{PO}_{4}+10 \mathrm{~nm} \quad \mathrm{Al}_{2} \mathrm{O}_{3} \text { after } \\
1^{\prime} 40^{\prime \prime} \text { in } \mathrm{ALD}\end{array}$ \\
\hline
\end{tabular}

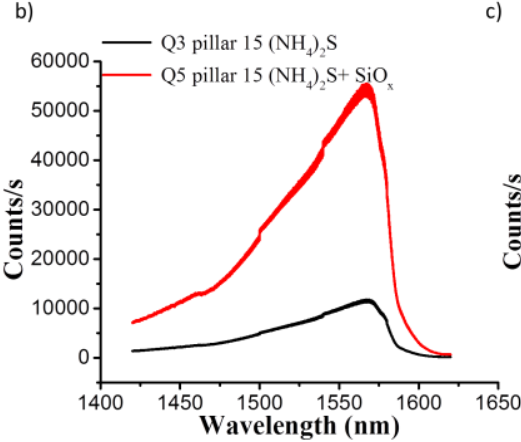

c)

Figure 2 a) Table of passivation methods used on the etched pillars, b) $\mu \mathrm{PL}$ measurements for samples encapsulated in $\mathrm{SiO}_{\mathrm{x}}$ and $\mathrm{Al}_{2} \mathrm{O}_{3}$ with oxygen plasma method c) $\mu \mathrm{PL}$ measurements for samples encapsulated in $\mathrm{SiO}_{\mathrm{x}}$ and $\mathrm{Al}_{2} \mathrm{O}_{3}$ with ammonium sulfide method.

\section{Characterization and results}

To characterize the passivation quality we performed $\mu$ PL and TRPL measurements shown in Figure 2 b, c). First we measured the PL of each of the 15 pillars from R1-Q1 to R1-Q7. Then, we performed TRPL measurements on each pillar to measure the lifetime of the carriers while exciting the pillars with a laser pulse. Experiments performed with oxygen plasma treatment and those with ALD encapsulation showed poor passivation performance. Thus we only report the results obtained from sample R1-Q5 passivated with $\left(\mathrm{NH}_{4}\right)_{2} \mathrm{~S}$ and encapsulated with $\mathrm{SiO}_{\mathrm{x}}$. In order to measure the ratio of increment in PL and TRPL we compared R1-Q5 with R1-Q3 only passivated with $\left(\mathrm{NH}_{4}\right)_{2} \mathrm{~S}$.

We can summarize $\mu$ PL experiments in Figure 2b, c). A strong improvement of the $\mu$ PL intensity (by 5 and 22 times for big and small pillars respectively) using ammonium sulfide treatment is observed. The graphs depict the integrated spectra for two types of pillars; pillar 15 with $3.4 \mu \mathrm{m}$ cross-section side (Fig 2b), and pillar 1 with $270 \mathrm{~nm}$ side.

Regarding TRPL measurements, we employed a time-correlated single photon counting to investigate the carrier dynamics in InP/InGaAs/InP nanopillars with varying cross section. In the experiment, we optically pumped the 
nanopillars using a pulsed laser at $968 \mathrm{~nm}$ with a periodic pulse train at $10 \mathrm{MHz}$ and pulse width $<100 \mathrm{ps}$. The photoluminescence was coupled into a single mode optical fiber using a microscope objective and then guided to a superconducting single photon detector (SSPD). For the TR measurements, a histogram of photon arrival times was built by correlating the SSPD output with the pulse pattern generator trigger with a correlation card (Pico Harp 300). As expected, sample R1-Q5 shows longer carrier lifetimes for all pillars sizes (from 0.27 to $3.4 \mu \mathrm{m}$ ). Figure 3a) shows the lifetime comparison of a sub-micron cross-section pillar of $270 \mathrm{~nm}$ between the untreated sample (black), and the ones passivated with $\left(\mathrm{NH}_{4}\right)_{2} \mathrm{~S}$ (blue) and $\left(\mathrm{NH}_{4}\right)_{2} \mathrm{~S}+\mathrm{SiO}_{\mathrm{x}}$ (red). Impressive lifetimes of $24 \mathrm{~ns}$ (and $46 \mathrm{~ns}$ for $570 \mathrm{~nm}$ side pillar) were recorded. It has been demonstrated elsewhere that the lifetime of bulk InGaAs can achieve values of even $100 \mathrm{~ns}$ [5]. The implication of such long lifetimes is an extreme reduction of the surface recombination of the pillars. The surface recombination was estimated by performing a linear fit of the carrier lifetimes using the equation $1 / \tau_{P L}=1 / \tau_{b}+2 S / d$ [2], where $\tau_{P L}$ is the effective carrier lifetime, $\tau_{b}$ is the carrier lifetime in the bulk material, $S$ is the surface velocity, and $d$ is the side length of the pillar with square cross-section. Figure $3 b$ ) shows the experimental data with sub-micron pillars and the linear fit from which the surface recombination is extracted. An ultra-low surface recombination of around $530 \mathrm{~cm} / \mathrm{s}$ is estimated, which is to our knowledge a record low surface recombination for deeply etched sub-micron $p n$-junctions. This value is two orders of magnitude lower than the surface recombination velocity for the un-passivated samples, estimated to be $\sim 1.2 \times 10^{4}$ $\mathrm{cm} / \mathrm{s}$.
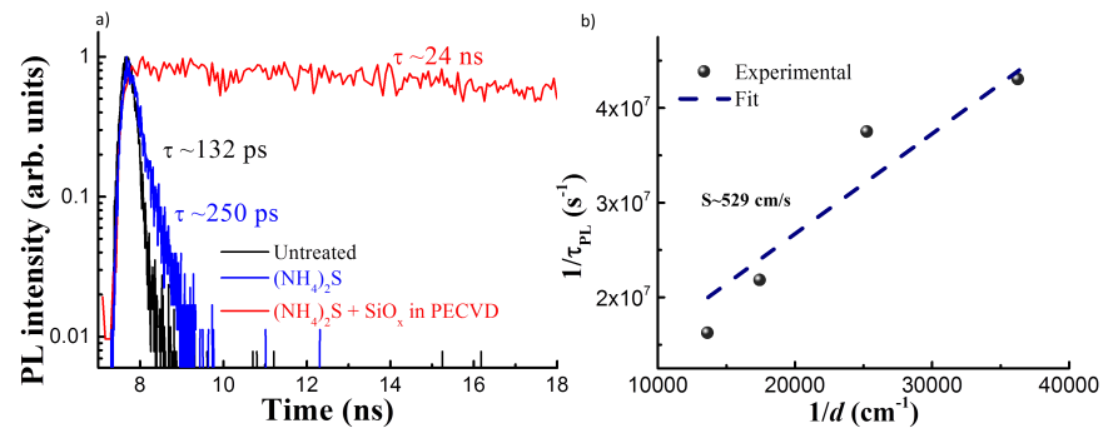

Figure 3 a) TRPL for a $270 \mathrm{~nm}$ side length pillar: untreated, with $\left(\mathrm{NH}_{4}\right)_{2} \mathrm{~S}$ and with $\left(\mathrm{NH}_{4}\right)_{2} \mathrm{~S}+\mathrm{SiO}_{x}$, b) Surface recombination velocity of submicron pillars with $\left(\mathrm{NH}_{4}\right)_{2} \mathrm{~S}+\mathrm{SiO}_{\mathrm{x}}$ treatment.

\section{Conclusions}

We tested two different passivation processes with a series of cycles of oxygen plasma and ammonium sulfide plus a thin capping of $\mathrm{SiO}_{\mathrm{x}}$ or $\mathrm{Al}_{2} \mathrm{O}_{3}$. We demonstrated a robust passivation process with $\left(\mathrm{NH}_{4}\right)_{2} \mathrm{~S}+$ thin $\mathrm{SiO}_{\mathrm{x}}$ capping. The passivation process is lasting and reliable. To prove it, we measured samples again after some days and retrieved the same excellent values. We obtained from the integrated $\mu$ PL measurements around 100x better results in comparison with samples without passivation and TRPL that resulted in impressive carrier lifetimes of $46 \mathrm{~ns}$ for sub-micron side pillars, a value close to the bulk material. With the long lifetimes we were able to estimate an ultralow surface recombination value of $530 \mathrm{~cm} / \mathrm{s}$; which, to the best of our knowledge, is a record low value of surface recombination velocity for deeply etched III-V nano $p n$ - junctions. These results are highly encouraging for the fabrication of electrically pumped sub- $\mu \mathrm{m}$ lasers or any active deeply etched sub- $\mu \mathrm{m}$ device.

We acknowledge support of ERC Advance Grant NOLIMITS and Marie Skłodowska-Curie 2014-IF-659012 for founding our research.

\section{References}

[1] M.T, Hill and Malte C. Gather,"Advance in small lasers", Nat. Photon.8, 2014.

[2] Ding et al, “Metallic subwavelength-cavity semiconductor nanolasers”, Light: Science \& Applications, e20, 2012.

[3] Crosnier, G., Bazin, A., et al, "Subduing surface recombination for continuous-wave operation of photonic crystal nanolasers integrated on Silicon waveguides”. Optics Express, 23(21), 27953, 2015.

[4] Boroditsky, M., Gontijo, I., et al., "Surface recombination measurements on III-V candidate materials for nanostructure light-emitting diodes”. Journal of Applied Physics, 87(7), 3497, 2000.

[5] Komolibus, K., Scofield, et al., “Complex emission dynamics from InGaAs/GaAs core-shell nanopillars”, Proc. of SPIE Vol. $9373,2015$. 